\title{
Enhancement of perceptual sensitivity as the result of selectively attending to spatial locations
}

\author{
HOWARD S. BASHINSKI \\ University of Colorado, Boulder, Colorado 80309 \\ and \\ VERNE R. BACHARACH \\ Acadia University, Wolfville, Nova Scotia BOP IXO, Canada
}

\begin{abstract}
The present experiment employed a visual signal-detection task within a cost-benefit (inhibitionfacilitation) paradigm to examine the effects of selective attention on perceptual sensitivity. A central cue directed the subjects' attention to either a right or a left spatial location where a detection task was performed. The cue was either a high/low or neutral-validity indicator of the position in which an event was likely to occur. A rating-scale response scheme in conjunction with the subjects' target signal locational judgments allowed for the construction of ROC curves for each condition. Significant benefits were found for all subjects, supporting the hypothesis that selective attention can enhance perceptual sensitivity. Deallocation of attention resulted in an inhibition of sensitivity in unattended spatial locations. Subjects were consistently most sensitive in the right spatial location. There were no significant differences in overall response bias among the three conditions or in spatial locations. The results support theories of attention, such as "perceptual tuning," that suggest very early selective control.
\end{abstract}

Can we shift our attention without moving our eyes? Early introspective analyses indicated that this was possible (Helmholtz, 1909/1962), and modern research seems to have confirmed the independence of gaze and visual attention (Engel, 1971; Eriksen \& Hoffman, 1973; Kaufman \& Richards, 1969; Posner, Nissen, \& Ogden, 1978; Shaw \& Shaw, 1977; Van Voorhis \& Hillyard, 1977; Jonides, Note 1). This is not to suggest that attention and eye movements are unrelated. In the usual case, shifts of attention are accompanied by shifts in eye position. Jonides (Note 1) has shown that information in the visual periphery is especially effective in drawing both attention and eye fixations, suggesting that "perhaps ... movements of the mind's eye are intimately related (in an as yet unspecified way) to movements of the body's eye." However, Klein (1980), for example, has investigated the possibility that readiness to move one's eyes to a spatial location mediates cognitive attentional control and has found that it does not.

The present study was submitted by the first author to the psychology department at Acadia University in partial fulfillment of the requirements for the Master of Science degree. The study was supported by Natural Science and Engineering Research Council of Canada Grant A-0665 awarded to the second author. The authors are pleased to thank Ray Klein for his valuable suggestions regarding experimental design, Donald Dorfman for his suggestions regarding measures of sensitivity, and Lewis Harvey, Jr., for his comments on the final draft. Reprint requests should be sent 10 Howard S. Bashinski, Psychology Department, University of Colorado, Boulder, Colorado 80309
The fact that attention and eye movements can be independent leads to a second interesting question. That is, if we shift only our attention to a spatial location, is the processing of information at that location facilitated? Increases in sensitivity at attended spatial locations imply very early voluntary control of selective processes. Carr and Bacharach (1976) conducted an extensive review of the literature relevant to sensory input regulation and concluded that voluntary control can be exercised at a very early point along the processing pathway. They referred to that early input selection as a process of "perceptual tuning," a notion conceptually similar to stimulus set. In addition, theorists such as Kahneman (1973), Keele (1973), Neisser (1967), and Posner and Boies (1971) all assume the possibility of very early attentional selection. Clear processing benefits for attended inputs have been demonstrated by a number of investigators (Blaha, 1971; Eriksen \& Hoffman, 1972a, 1972b, 1973, 1974; Posner, Nissen, \& Ogden, 1978; Remington, 1978; Van Der Heijden \& Eerland, 1973). However, other researchers have concluded that selective attention does not facilitate the processing of attended information or input from an attended spatial location (Grindley \& Townsend, 1968; Mertens, 1956; Mowrer, 1941; Shiffrin \& Gardner, 1972; Shiffrin \& Grantham, 1974; Shiffrin, McKay, \& Shaffer, 1976).

Jonides (Note 1) suggests that most of the studies showing enhancement effects of spatial selective attention involve the use of a peripheral as opposed to 
a central cue to the spatial location to be attended. It appears that it is easier to draw attention to the periphery than it is to direct it. This argument, however does not hold for all cases (e.g., Posner et al., 1978; Remington, 1978). In a more general sense, demonstration of attentional effects seems most directly related to two variables: the ability of the particular experimental procedure to produce real changes in attentional allocation, and (2) the type of dependent measures used to index facilitation.

Paradigms that involve the manipulation of the probability of a stimulus occurring at different locations are very effective in producing changes in visual attentional allocation. Failure to produce these changes appears to have been the problem in both the Mertens (1956) and Mowrer (1941) studies. This problem is also common to experimental procedures in which the probable stimulus location is known exactly; the resulting data can show benefits for an attended location but offer no information about unattended locations (Blaha, 1971).

Posner and Snyder (1975a, 1975b) have developed an experimental paradigm that appears to be very sensitive to changes in attentional allocation. Based on Kahneman's (1973) theory of attentional selection, the procedure was developed on the assumption that attention is associated with a central processing system of limited capacity. That is, attending to one input necessarily decreases the amount of attention available for other inputs. Although the procedure was originally used in letter-matching studies, it has been adapted for use in experiments on visual selective attention (Posner et al., 1978; Remington, 1978; Posner, Davidson, \& Nissen, Note 2). Basically, a subject receives advance information about the probability of an event's occurring at any particular spatial location. The subject is then induced to shift attentional allocation on the basis of this advance probabilistic information, and the resulting data indicate the degree to which attention is allocated among the various locations. Facilitation due to attentional allocation is referred to as benefit, and inhibition due to deallocation is referred to as cost. This cost-benefit procedure is employed in the present study.

Once one has developed a probabilistic framework for attentional manipulation, it is necessary to employ a dependent measure that effectively indexes visual sensitivity changes and directly reflects the behavioral consequences of attentional shifts. It appears that visual signal-detection tasks are especially sensitive to shifts in attentional allocation (Blaha, 1971; Remington, 1978). Furthermore, signal-detection procedures and analyses offer a means of separating changes in observers' sensory processes from changes in decision processes. Attentional shifts effecting changes in sensory emphasis are most likely to be reflected as changes in the mean of the signal plus noise distribution among experimental conditions. On the other hand, attentional shifts resulting primarily in changes in decision processes will be evidenced by changes in the beta variable. The present study was designed to show changes in attentional allocation across the visual field in a simple detection task using the signaldetection paradigm. Both Blaha (1971) and Remington (1978) have employed similar methodologies. However, Remington's experimental design did not allow for the calculation of false alarm rates for each condition, and Blaha failed to obtain a measure of performance at unattended spatial locations. The current study allowed for the calculation of all the relevant response probabilities and for the construction of ROC curves for each observer under each stimulus condition.

The participants in the present study were directed to shift their attention to a particular spatial location in anticipation of a visual target's occurring at that location. The validity of the locational cue used to direct attention was varied from approximately .80 to .20. Subjects responded by indicating target occurrence, rating confidence in their decision, and giving the location of the target if the decision was positive. The area under the ROC curve, $P(A)$, was the principal performance measure. This parameter has the advantage of being relatively independent of the variances or shape of the underlying distributions of signal and noise (Green \& Swets, 1974; Simpson \& Fitter, 1973; Dorfman, Note 3). However, when the variances are equal and the distributions normal, $\mathrm{z}(\mathrm{A}) \cdot \sqrt{2}=\mathrm{d}^{\prime}$. In the current context, $\mathrm{P}(\mathrm{A})$ values associated with high-probability cues should diverge positively from those of neutral cues, and lowprobability cues should reflect negative divergence.

\section{METHOD}

\begin{abstract}
Apparatus
A Gerbrands G1135, Model T-4A, four-field Harvard tachistoscope with an attached automatic card changer and logic interface was used to present the stimuli. The distance between the subject's eye and the stimulus card was $77 \mathrm{~cm}$. Viewing was binocular with no artificial pupils employed. The fixation point was a black dot $6.5 \mathrm{~min}$ of visual angle in diameter. Each viewing field was $6 \mathrm{deg} 42 \mathrm{~min} \times 9 \mathrm{deg} 28 \mathrm{~min}$ in visual angle.
\end{abstract}

\section{Material}

All stimuli were printed in black ink on Gerbrands G1147 white cards. Locational cues, printed on separate cards, were a plus sign and a right or left arrow. The plus sign was $22 \mathrm{~min} \times$ $22 \mathrm{~min}$ in visual angle and the arrows subtended $22 \mathrm{~min}$. The target was a zero $18 \mathrm{~min}$ in diameter printed $3 \mathrm{deg} 43 \mathrm{~min}$ directly to the right or left of the fixation point.

\section{Subjects \\ Three female undergraduate psychology students served as paid volunteers, receiving $\$ 50.00$ for their participation. Each had normal or corrected-to-normal vision. None had had prior ex- perience in controlled psychophysical observation.}

\section{Design}

The study was conducted within the framework of the ratingscale signal-detection procedure. The a priori probability of a target occurrence was held constant at .5. The only factor directly 
manipulated was the validity of a cue to the probable location of a target occurrence. On each trial, either a neutral cue (plus sign) or high /low validity cue (arrow) was presented. The plus sign indicated that the target, if it occurred, was equally probable on the right or left. The arrow indicated that the target, if it occurred, would occur in the direction of the arrow approximately $80 \%$ of the time. Using these cues, detection data were obtained at three levels of the validity factor, high $(p=.8)$, neutral $(p=.5)$, and low $(p=.2)$, for each subject.

Each block of trials consisted of 72 neutral, 36 right-arrow, and 36 left-arrow cue presentations. For each cue condition, $50 \%$ of the trials were catch trials.

\section{Procedure}

Each subject participated in nine experimental sessions lasting approximately $2 \mathrm{~h}$ each. Each session consisted of four blocks of 144 trials, with a 5-min break between the first and last two blocks and a 10 -min break between Blocks 2 and 3 . The experiment consisted of two phases. Phase 1 , the training phase, was conducted during the first two experimental sessions, with the remaining seven sessions constituting Phase 2 . Two of the subjects completed all nine experimental sessions within 3 weeks; the third completed them within 5 weeks.

Phase 1a. This phase served as the subject's introduction to both the signal-detection and the basic outline of the experiment. Written general instructions detailed the structure of the experimental sessions and described the general procedure to be used throughout the experiment. The subjects were fully informed of the purpose of the experiment and assured that at no point would any type of deception be a part of the procedure.

After the instructions were read and understood, noise-reducing headphones were placed over the subjects' ears and they assumed a position at the tachistoscope viewing hood. Field 1, containing the fixation point, was illuminated. Subjects were instructed that the fixation point would be present between each trial and that they were to focus their eyes upon it. After $60 \mathrm{sec}$ of field adaptation, the experimenter indicated that the subject could begin the trial by pressing a hand-held button. It was stressed that a trial should not be initiated until fixation had been achieved. Phase la consisted of 144 trials, each with the following sequence of events: One second after the buttonpress, the fixation point was replaced by the plus sign for $180 \mathrm{msec}$. This was then replaced by either a target on the left or right or a blank for $100 \mathrm{msec}$. The end of the trial was indicated by the reappearance of the fixation point immediately following target termination.

The subjects responded by saying "yes" if they detected a target and "no" if they did not. They rated their responses using the following scale: (1) uncertain, (2) fairly certain, and (3) absolutely certain that their response was correct. In addition, on "yes" trials, the subjects indicated whether the target occurred on the right or left. A locational response was not required on "no" trials (even when the target was presented) because it was felt this would create confusion on the part of the subjects that would detract from the primary detection task. Verbal feedback regarding target occurrence was given immediately by the experimenter, and the subjects' responses were manually recorded. The automatic card feeder then advanced the next stimulus card into position. This made a noise that could be heard by the subjects and was the signal that they could proceed with the next trial.

The subjects were instructed that their performance goal was to maximize hits and minimize false alarms. Each hit was assigned a value of +1 and each false alarm a value of -1 . At the end of each block of trials, the subjects were told their point totals. As an added incentive, the subjects were told that there would be a $\$ 10.00$ bonus at the end of the experiment for the subject with the highest point total.

Phase 1b. In this phase of the experiment, a baseline measure was obtained of each subject's sensitivity to the target in the neutral condition, using the plus sign as the locational cue. The procedure was exactly the same as in Phase la except that the presentation time of the target was greatly reduced. Three blocks of 144 trials were run, one block at each of three presentation speeds. A pilot study indicated that $\mathrm{d}^{\prime}$ values close to 1.0 could be obtained for most subjects with presentation speeds between 10 and $20 \mathrm{msec}$. This d' value corresponds to a $\mathrm{P}(\mathrm{A})$ of .7611 , assuming equal variance, and was considered to be a good reference for detecting sensitivity changes. Therefore, three blocks were run with stimulus presentation times of 20,15 , and $10 \mathrm{msec}$, in descending order, and a crude psychometric function for each subject was generated. From these functions, presentation speeds for each subject were determined as follows: Subject A.T., $12 \mathrm{msec}$; Subject M.W., $15 \mathrm{msec}$; Subject W.C., $13 \mathrm{msec}$. These values were employed in Phase 2.

Phase 1c. This phase introduced the subjects to the arrow cues. The instructions indicated that the probability of a target in the direction of an arrow, if a target occurred, was .8. The instructions pointed out that, over the long run, it would probably be worthwhile in terms of performance to try to shift attention in the direction of the arrow.

During this phase, target presentation speed was increased to $100 \mathrm{msec}$, allowing the subjects to become familiar with the probability relationships associated with the arrow cue. This phase consisted of one block of 144 trials.

Phase 2. This was the main experimental phase of the experiment. All instructions were identical to those used in Phase 1c. Only the target presentation speed was changed, using the values determined for each subject in Phase $1 \mathrm{~b}$. Phase 2 consisted of 31 blocks of 144 trials.

During this phase, each cue was presented for $180 \mathrm{msec}$, followed immediately by target, or blank, presentation. The maximum total time for cue plus target presentation was $196 \mathrm{msec}$, precluding the possibility of completing eye movements and focusing on the stimulus event prior to stimulus termination (Colegate, Hoffman, \& Eriksen, 1973; Jonides, Note 1).

\section{RESULTS}

The data in this experiment were subjected to a variety of analyses, based primarily upon the assumptions of signal-detection theory. Using the maximum-likelihood approach described by Dorfman and Alf (1969), computer-determined estimates were obtained for the sensitivity parameter $\mathrm{P}(\mathrm{A})$ and its variance, along with a number of related measures, for each subject under each cue condition. From these data, the associated costs and benefits were calculated and tested for statistical significance. The signal-detection analyses were applied in a hierarchical fashion, first to the detection data alone and then to detection plus localization. Estimates of response bias $(\beta)$ were also calculated in order to determine whether the subjects' decision criteria were influenced by the manipulation.

\section{Sensitivity}

Detection. An initial analysis was performed on the detection data for each subject in each of the three cue-validity conditions. The $\mathrm{P}(\mathrm{A})$ values for the neutral validity condition were $.73, .70$, and .71 for Subjects M.W., A.T., and W.C., respectively. These are very near the .76 value corresponding to a d' of 1.0 that was used as a reference for determining stimulus presentation times for each subject.

The same procedure was applied to the data from the high- and low-validity cue conditions. In our 
design, directional cue validity was ultimately conditional upon the location of the target. Therefore, it was not possible to distinguish between high- and low-validity false alarms on the basis of the detection data alone. It was necessary to employ pooled blank trial data in the analysis of these two conditions. The resulting $\mathrm{P}(\mathrm{A})$ values for each subject are contained in the "Detection" section of Table 1. The values designated "Overall" are based on the pooled raw response data of all three subjects.

Table 1 also contains estimates of the $G$ parameter suggested by Gourevitch and Galanter (1967). This is basically a large-sample $t$ test and the required assumptions have been met. The appropriate procedures for unequal sample size and corrections for unequal variances have also been applied (see Ferguson, 1966). We rejected the null hypotheses of no difference between $P(A)$ values if $p<.05$. It is evident that the high-validity cue produced a substantial sensitivity benefit for each subject. However, no significant costs were associated with the low-validity cue.

In order to clarify the nature of the attentional effects, overall hit and false alarm rates (HR, FAR) were calculated for each condition. The resulting values were $(.53, .22),(.56, .22)$, and $(.83, .22)$ for the low-, neutral-, and high-validity conditions, respectively. One might expect that attentional allocation would increase HR and decrease FAR, and that deallocation would have the opposite effect. The results reflect the postulated changes in HR. Unfortunately, pooling of the blank trial data for the low- and high-validity conditions obscures any meaningful changes that may have occurred in FAR. For this reason, we propose to make use of the subjects' locational responses as a means of partitioning the false alarms into cue-validity conditions.
Detection plus localization: I. The primary reason for asking subjects to localize their "yes" responses was to attempt a conditional classification of the false alarms. For example, the response "yes-one-left" to a blank trial cued with a right arrow might be considered a low-validity false alarm. Restated, we find it appropriate to consider under what cue-validity condition a particular blank trial (on which a false alarm occurred) would fall if it had been a target trial, as the subject reported. This seems reasonable because, by definition, hits and false alarms are the result of quantitatively exceeding some criterion value of sensory experience. However, we must first examine the relationships between detection and localization in the present context.

The subject's primary task was stimulus detection, and only after detection had occurred was a localization response required. Localization can, in this particular case, be conceived of as a two-alternative forced-choice task, and analysis of the localization data in this manner yielded overall $P(A)$ values of $.93, .95$, and .94 for Subjects A.T., M.W., and W.C., respectively. For each subject, the largest $\mathrm{P}(\mathrm{A})$ value was associated with the high-validity cue.

It is apparent that once detection has been made, localization is extremely accurate. In view of the correlation between these two tasks in the present experiment, we find it appropriate to consider the accuracy of detection plus localization. For this purpose, we employ the "joint" ROC as proposed by Starr, Metz, Lusted, and Goodenough (1975), and recently illustrated by Swets, Pickett, Whitehead, Getty, Schnur, Swets, and Freeman (1979). The false alarm rates remain the same as in our detection ROCs. However, hits are now classified with respect to correct detection plus localization. Figure 1 illustrates normal-normal ROCs for Subject W.C. based on

Table 1

Summary of Experimental Results for Each Subject Under All Conditions and Analyses

\begin{tabular}{|c|c|c|c|c|c|c|c|}
\hline Subject & $\mathrm{P}(\mathrm{A}) 1$ & $P(A) n$ & $\mathrm{P}(\mathrm{A}) \mathrm{h}$ & Benefit & $G(h-n)$ & Cost & $G(n-1)$ \\
\hline & \multicolumn{7}{|c|}{ Detection } \\
\hline A.T. & .698 & .701 & .885 & .184 & $13.9^{*}$ & .003 & .132 \\
\hline W.C. & .743 & .711 & .888 & .177 & $13.5^{*}$ & & \\
\hline M.W. & .707 & .731 & .886 & .155 & $12.1^{*}$ & .024 & 1.080 \\
\hline \multirow[t]{2}{*}{ Overall } & .715 & .712 & .883 & .171 & $22.7^{*}$ & & \\
\hline & \multicolumn{7}{|c|}{ Detection + Localization - I } \\
\hline A.T. & .690 & .681 & .886 & .205 & $14.9 *$ & & \\
\hline W.C. & .734 & .699 & .886 & .187 & $14.1^{*}$ & & \\
\hline M.W. & .678 & .720 & .885 & .165 & $12.7 *$ & .042 & $1.800 \dagger$ \\
\hline \multirow[t]{2}{*}{ Overall } & .702 & .698 & .882 & .180 & $23.7^{*}$ & & \\
\hline & \multicolumn{7}{|c|}{ Detection + Localization - II } \\
\hline A.T. & .567 & .681 & .897 & .216 & $15.8 *$ & .114 & $4.800 \dagger$ \\
\hline W.C. & .654 & .699 & .897 & .198 & $15.0^{*}$ & .045 & $1.900^{\dagger}$ \\
\hline M.W. & .685 & .720 & .885 & .165 & $12.7^{*}$ & .035 & $1.500^{\dagger}$ \\
\hline Overall & .628 & .698 & .891 & .193 & $25.0^{*}$ & .070 & $5.200 \dagger$ \\
\hline
\end{tabular}

Note-l = low-validity cues; $n=$ neutral cues; $h=$ high-validity cues.

$*^{*} \dot{p}<.0001$, one-tailed test.

$t_{p}<.04$, one-tailed test. 


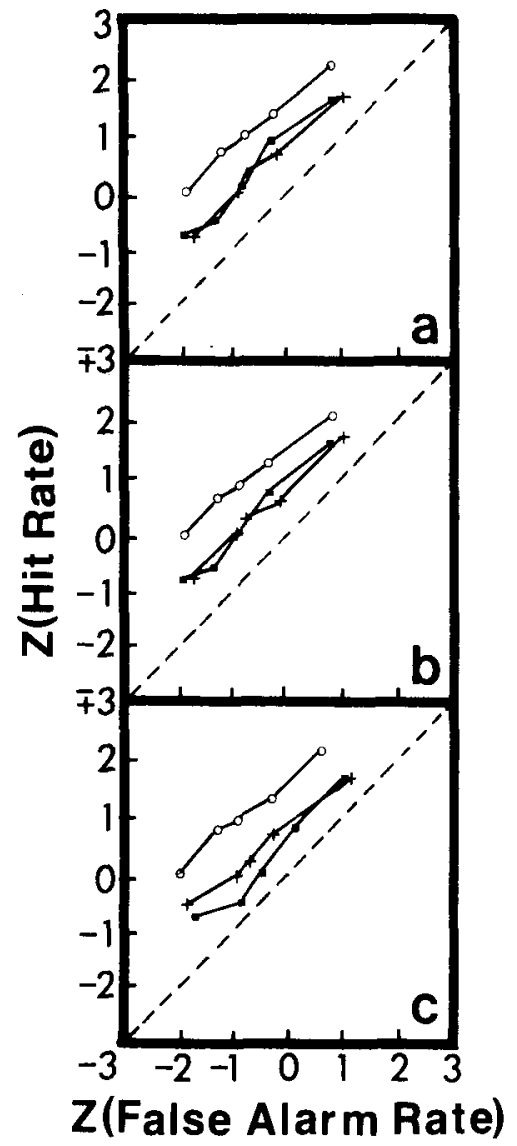

Figure 1. ROC curves for each cue condition and analysis for Subject W.C. The analyses are (a) Detection, (b) Detection + Localization-I, and (c) Detection + Localization-II ( $=$ = low validity; $+=$ neutral validity; $O=$ high validity).

detection alone (1a) and on detection plus localization (1b). The curves are nearly identical. The "Detection + Localization-I" section of Table 1 contains the $\mathrm{P}(\mathrm{A})$ values resulting from this analysis.

Detection plus localization: II. The results above support the validity of jointly considering detection and localization, at least in the context of the present experiment. We have examined the implication this holds for the hit responses and have found no significant changes from the detection analysis. We now examine the consequences of partitioning the false alarms into cue-validity conditions by referencing the localization responses.

The results of this analysis are contained in the "Detection + Localization-II" section of Table 1 and are illustrated in Figure 1c for Subject W.C. By comparison with the results of the detection-alone analysis, the partitioning of the false alarms resulted primarily in a decrease of $\mathrm{P}(\mathrm{A})$ values in the lowvalidity cue condition. Consequently, two of the three subjects now show significant costs of attending to the location indicated by a cue that was ultimately invalid. The overall partitioned false alarm rates were .37 and .17 for the low- and high-validity conditions, respectively. Thus, the primary attentional effects were an increase in $\mathrm{HR}$ due to allocation and an increase in FAR due to deallocation.

Figure 2 illustrates normal-normal ROC functions for each subject in each cue condition as determined employing the "Detection + Localization-II" approach. They are based on the maximum-likelihood solutions of Dorfman and Alf (1969). These curves are typical of those obtained with detection data, their most important aspect being a systematic change in slope across conditions. Specifically, all of the decreases in slope that are apparent upon visual inspection are significant $(p<.05)$, with the exception of the low/neutral case for Subject A.T.

It should be noted that the analyses described above were applied to data pooled across right/left spatial location. In order to assess the nature of any possible locational effects, identical analyses were performed on the unpooled data. P(A) values were consistently greater on the right than on the left, with the exception of the low-validity condition for Subjects A.T. and W.C. In these two cases, the right/left difference failed to meet the criterion for statistical significance. The differences in $\mathrm{P}(\mathrm{A})$ values between cue conditions (within subjects) were also tested in the unpooled data and were found to be consistent with the results for the pooled data. That is, benefits with no costs were evident in the Detection and Detection + Localization-I analyses, and the Detection + Localization-II analysis yielded benefits and costs.

\section{Response Bias}

In order to obtain an indication of the success of the instructions to maximize hits and minimize false

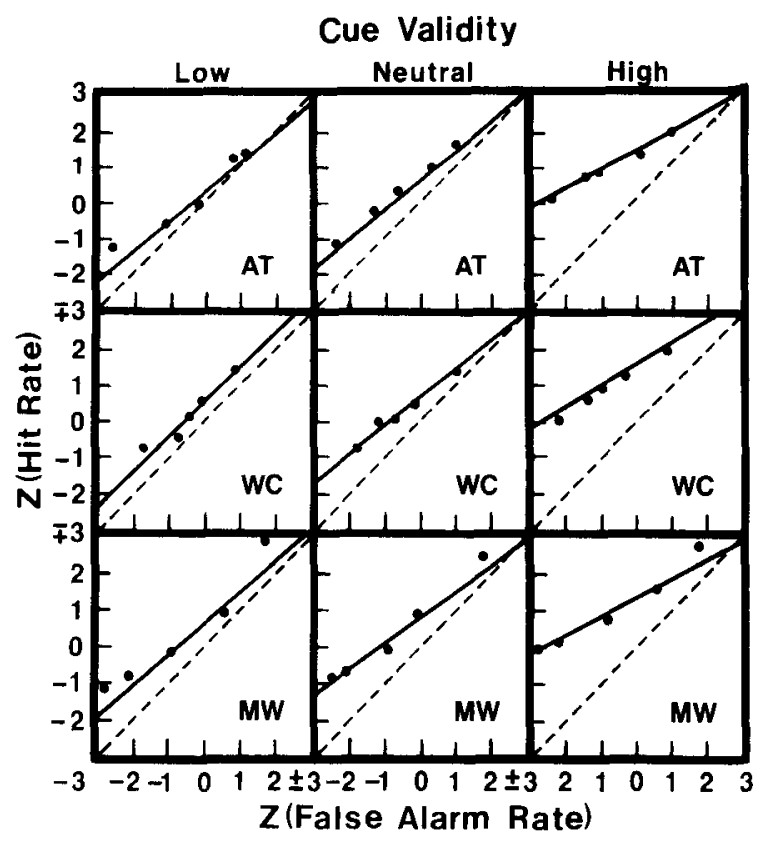

Figure 2. Normal-normal ROC curves for each cue condition for each subject (based on maximum-likelihood solution). 
Table 2

Average Beta Values for Each Cue Validity Condition and Analysis

\begin{tabular}{lccc} 
& \multicolumn{3}{c}{ Cue Validity } \\
\cline { 2 - 4 } \multicolumn{1}{c}{ Analysis } & Low & Neutral & High \\
\hline Detection & 1.2 & 1.3 & 1.2 \\
Detection + Localization - I & 1.1 & 1.2 & 1.1 \\
Detection + Localization - II & 1.2 & 1.4 & 1.2 \\
\hline
\end{tabular}

alarms, the data were collapsed into two categories (i.e., yes-no) and an overall $\beta$ calculated for each subject under each cue condition. These values were averaged to provide an indicator of response bias across subjects under the three conditions. Table 2 contains the resulting $\beta$ values for each analytical approach. These results indicate excellent maximization of performance $(\beta=1.0)$ and stable decision criteria across analyses and conditions. Analyses with respect to spatial location indicated overall values of 1.3 and 1.1 for the right and left, respectively.

\section{DISCUSSION}

The results of this experiment support the hypothesis that visual sensitivity to events occurring at a particular spatial location can be enhanced by the allocation of attention to that location. Strong evidence to this effect was produced by a locational cue that temporally allowed for only the shifting of attention and not the eyes. Facilitation occurred in the absence of any significant criterion shifts, suggesting operation at the early levels of sensory processing. In addition, partitioning of the false alarms into cue-validity conditions revealed significant inhibition of sensitivity as the result of attentional deallocation.

The obtained values for costs (inhibition) and benefits (facilitation) indicate a relationship consistent with the formulation described by Posner and his colleagues (Posner \& Boies, 1971; Posner \& Klein, 1973; Posner et al., 1978; Posner \& Snyder, 1975a, 1975b; Posner, Nissen, \& Ogden, Note 4.) They make a general distinction between automatic and conscious, or attended, processing. An input item may automatically activate a specific processing pathway and facilitate processing of items sharing that pathway. This automatic activation produces benefits but no costs. However, consciously attending to an input item increases the degree of facilitation and at the same time inhibits the processing of other items.

Remington (1978) has suggested that visual spatial attention may also operate in both automatic and attended modes. Automatic activation can be described in terms of systems that extract information from a specific location in space. The present study does not preclude the possibility of automatic spatial activation. Indeed, Subject M.W. showed marked facilitation with only marginally significant inhibition, suggesting the possibility that, over the course of the experiment, the attentional shifts may have involved less and less central capacity. Alternatively, the shifts may have been easier for this subject from the outset of the experiment.

The curves in Figure 2 clearly reflect the asymmetrical relationship between facilitation and inhibition often found when attention is manipulated in a probabilistic manner. That is, benefits are typically greater than costs (Posner \& Snyder, 1975a, 1975b). It should be noted that these results were obtained using central cues, producing what Remington (1978) has referred to as internally generated shifts of attention. Jonides (Note 1) has shown that externally generated shifts of attention (i.e., produced using peripheral cues) typically produce greater inhibition than do internally generated shifts.

An important feature of this study is the generation of ROC curves for each subject under each condition. Previous studies involving a detection paradigm either have been unable to determine the false alarm rates associated with each condition or have based sensitivity estimates on only one pair of hit and false alarm rates. By defining the ROC curves, the reliability of the $P(A)$ measure employed in this study is increased. In addition, the decreases in slope across conditions are precisely what one would expect if the conditions represented increasing levels of signal strength (Green \& Swets, 1974).

It has been suggested that changes in sensitivity reflect changes in stimulus set, whereas changes in $\beta$ reflect changes in response set (Broadbent, 1970; Broadbent \& Gregory, 1963, 1964). The current study found no significant changes in overall $\beta$ across the three conditions. Evidently, the priming technique was successful in creating a powerful attentional set, based on the spatial properties of the target itself.

The only unexpected result was that each subject was more sensitive to detection on the right than on the left. When questioned about this performance benefit, two of the subjects suggested that they could shift attention more rapidly from left to right because they read that way. This explanation assumes a functional relationship between attention and eye movements, and it is not yet clear exactly what that relationship might be. However, faster switching time for left/right over right/left attentional shifts is an intuitively pleasing explanation for the results. It should be noted that all three subjects were righthanded, and an explanation in terms of cerebral hemispheric differences is possibly in order.

The observed changes in $\mathbf{P}(\mathrm{A})$ values for low-, neutral-, and high-validity cues indicate that the subjects were able to allocate attention rapidly across the visual field, even though target events occurred at only two spatial locations. This contradicts the notion that attentional effects operate only when sufficient distractor items are present to exceed the span of 
apprehension (Grindley \& Townsend, 1968). Experiment 1 of the Grindley \& Townsend study employed four spatial locations. No differences were found when acuity performance in a known location condition (KL) was compared with an unknown location condition (UL). It is likely that the only real difference between these conditions was the size of the field to be attended. In the KL condition, a similar degree of attentional allocation was applied to one-quarter of the field. However, when distractor items were placed in the vacant locations, subjects were more accurate in the KL condition. The difference is that when the distractor items are present, the acuity task first requires detection of the target. If a simple detection task had been employed, changes in sensitivity would almost certainly have been found (Van Der Heijden \& Eerland, 1973).

The present study provided a situation in which the observers had to divide their attention between two adjacent spatial location. Locational cues produced varying degrees of certainty as opposed to two absolute (i.e., known and unknown) conditions. The detection procedure created a high degree of motivation on the part of the subjects to achieve maximum performance. Therefore, their attention was never totally dedicated to one position or the other, but allocated on the basis of cue validity.

Shiffrin and his colleagues have argued that attentional effects are not evident prior to short-term memory activation and other postperceptual processes (Shiffrin, 1975; Shiffrin \& Gardner, 1972; Shiffrin \& Grantham, 1974; Shiffrin et al., 1976). The sensory sensitivity changes produced in this study by attentional manipulation clearly refute these findings and add to contradictory evidence provided by other investigators (e.g., Beck \& Ambler, 1972; Eriksen \& Hoffman, 1973, 1974; Posner et al., 1978, Note 4). Beck and Ambler (1972) have suggested that the procedure in the Shiffrin and Gardner (1972) study may have precluded the operation of selective attention. In this experiment, a letter identification and localization task was compared in sequential and simultaneous conditions. No performance benefit was found for the sequential condition, a benefit that would have been expected if attention were operative. However, in their third experiment, the sequential stimuli were presented as a pair and compared with the presentation of four simultaneous stimuli. Beck and Ambler (1972) suggest that, under experimental conditions, a subject may be able to process two and four spatial locations with equal efficiency, thus accounting for the lack of discrepancy. Shiffrin (1975) reports similar findings using a choice detection task with $\mathrm{d}^{\prime}$ as the major dependent variable. In this case, it seems obvious that the two conditions (sequential and simultaneous) created a different decision problem for the observer. The likelihood that the stimulus occurred in any one sequential interval was conditional upon the decision made concerning the previous interval. Under these circumstances, one would expect to find changes in response bias as opposed to sensitivity.

\section{CONCLUSIONS}

The present results, combined with the above arguments and the harshly accurate critique by Keren and Skelton (1976) of Shiffrin et al. (1976), point clearly to the conclusion that selective attention influences very early visual perceptual processing. This appears to be true regardless of whether the target stimuli are foveal or peripheral (Posner et al., 1978, Note 4) and, in this study, supports a process similar to the "perceptual tuning" proposed by Carr and Bacharach (1976). Combining the probability manipulations of the cost-benefit paradigm with a simple detection task proved very effective in producing ROC curves for both facilitation and inhibition in the current study. In addition, the results strongly support capacity theories of attention (i.e., Kahneman, 1973; Keele, 1973) and the properties of attended processing suggested by Posner and his colleagues.

\section{REFERENCE NOTES}

1. Jonides, J. Voluntary versus reflexive control of the mind's eye's movement. Paper presented at the annual meeting of the Psychonomic Society, St. Louis, November 1976.

2. Posner, M. W., Davidson, B. J., \& Nissen, M. J. The process of stimulus detection. Paper presented at the annual meeting of the Psychonomic Society, St. Louis, November 1976.

3. Dorfman, D. D. Standard errors and confidence intervals for measures of sensitivity. Paper presented at the meetings of the Acoustical Society of America, Miami Beach, Florida, December 1977.

4. Posner, M. W., Nissen, M. J., \& Ogden, W. C. Attending to a position in space. Paper presented at the annual meeting of the Psychonomic Society, Denver, November 1975.

\section{REFERENCES}

Bеск, J., \& АмвLER, B. Discriminability differences in line slope and in line arrangement as a function of mask delay. Perception \& Psychophysics, 1972, 12, 33-38.

BLAнA, J. Visual information processing: Location uncertainty effects on target detection (Doctoral dissertation, Ohio State University, 1971). Dissertation Abstracts International, 32B, 3022. (University Microfilms No. 71-27, 432)

Broadbent, D. Stimulus set and response set: Two kinds of selective attention. In D. 1. Mostofsky (Ed.), Attention: Contemporary theory and analysis. New York: Meredith, 1970.

Broadbent, D., \& Gregory, M. Division of attention and the decision theory of signal detection. Proceedings of the Royal Society, 1963, 158, 222-231

Broadbent, D., \& Gregory, M. Stimulus set and response set: The alternation of attention. Quarterly Journal of Experimental Psychology, 1964, 16, 309-318.

Carr, T. H., \& Bacharach, V. R. Perceptual tuning and conscious attention: Systems of input regulation in visual information processing. Cognition, 1976, 4, 281-302.

Colegate, R. L., Hoffman, J. E., \& Eriksen, C. W. Selective encoding from multielement visual displays. Perception \& Psychophysics, 1973, 14, 217-224. 
Dorfman, D. D., \& AlF, E., JR. Maximum-likelihood estimation of parameters of signal-detection theory and determination of confidence intervals-rating-method data. Journal of Mathematical Psychology, 1969, 6, 487-496.

ENGEL. F. L. Visual conspicuity, directed attention and retinal locus. Vision Research, 1971, 11, 563-575.

Friksen, C. W., \& Hoffman, J. E. Some characteristics of selective attention in visual perception as determined by vocal reaction time. Perception \& Psychophysics, 1972, 11, 169. 171. (a)

Eriksen, C. W., \& Hofrman, J. E. Temporal and spatial characteristics of selective encoding from visual displays. Perception \& Psychophysics, 1972, 12, 201-204. (b)

Eriksen, C. W., \& Hoffman, J. E. The extent of processing of noise elements during selective encoding from visual displays. Perception \& Psychophysics, 1973, 14, 155-160.

Eriksen, C. W., \& Hoffman, J. E. Selective attention: Noise suppression or signal enhancement? Bulletin of the Psychonomic Society, 1974, 4, 587-589.

Ferguson, G. A. Statistical analysis in psychology and education. New York: McGraw-Hill, 1966.

Gourevitch, V., \& Galanter, E. A significance test for one parameter isosensitivity functions. Psychometrika, 1967, 32, 25-33.

Green, D. M., \& Swets, J. A. Signal detection theory and psychophysics. New York: Krieger, 1974.

Grindley, G. C., \& Townsend, V. Voluntary attention in peripheral vision and its effects on acuity and differential thresholds. Quarterly Journal of Experimental Psychology, $1968,20,11-19$.

Helmholtz, H. V. [Physiological optics] (Vol. 3; J. P. C. Southall, trans.). New York: Dover, 1962. (Originally published, 1909.)

Kahneman, D. Attention and effort. Englewood Cliffs, N.J: Prentice-Hall, 1973.

KaUfman, L., \& RichaRDs, W. Spontaneous fixation tendencies for visual forms. Perception \& Psychophysics, 1969, 5, 88-98.

KeEle, S. W. Attention and human performance. Pacific Palisades, Calif: Scott, Foresman, 1973.

Keren, S. W., \& Skelton, J. On selecting between theories of selective attention. Perception \& Psychophysics, 1976, 20, 85-88.

$K_{\mathrm{LE} \text { IN, }} \mathrm{R}$. Does oculomotor readiness mediate cognitive control of visual attention? In R. Nickerson (Ed.), Attention and performance VIII. Hillsdale, N.J: Erlbaum, 1980.

Mertens, J. J. Influence of knowledge of target location upon the probability of observation of peripherally observable test flashes. Journal of the Optical Society of America, 1956, 46, 1069-1070.

Mowrer, O. H. Preparatory set (expectancy): Further evidence for its "central" locus. Journal of Experimental Psychology, 1941, 28, 116-118.

Neisser, U. Cognitive psychology. New York: Meredith, 1967.
Posner, M. I., \& Boies, S. J. Components of attention. Psychological Review, 1971, 78, 391-408.

Posner, M. I., \& Klein, R. M. On the functions of consciousness. In S. Kornblum (Ed.), Attention and performance IV. New York: Academic Press, 1973.

Posner, M. I., Nissen, M. J., \& Ogden, W. C. Attended and unattended processing modes: The role of set for spatial location. In H. L. Pick, Jr., \& E. Saltzman (Eds.), Modes of perceiving and processing information. Hillsdale, N.J: Erlbaum, 1978 .

Posner, M. I., \& Snyder, C. R. R. Attention and cognitive control. In R. Solso (Ed.), Information processing and cognition: The Loyola Symposium. Hillsdale, N.J: Erlbaum, 1975. (a)

Posner, M. I., \& SNyder, C. R. R. Facilitation and inhibition in the processing of signals. In P. M. A. Rabbitt \& S. Dornic (Eds.), Attention and performance $V$. New York: Academic Press, 1975.

REMINGTON, R. W. Visual attention, detection and the control of saccadic eye movements. Unpublished doctoral dissertation, University of Oregon, 1978.

Shaw, M. L., \& Shaw, P. Optimal allocation of cognitive resources to spatial location. Journal of Experimental Psychol. ogy: Human Perception and Performance, 1977, 3, 201-211.

Shiffrin, R. M. The locus and role of attention in memory systems. In P. M. A. Rabbitt \& S. Dornic (Eds.), Attention and performance $V$. New York: Academic Press, 1975.

Shiffrin, R. M., \& Gardner, G. Visual processing capacity and attentional control. Journal of Experimental Psychology, 1972, 93, 72-83.

Shiffrin, R. M., \& Grantham, D. W. Can attention be allocated to sensory modalities? Perception \& Psychophysics, 1974, $15,460-474$.

Shiffrin, R. M., McKay, D. P., \& Shaffer, W. O. Attending to 49 spatial positions at once. Journal of Experimental Psychology: Human Perception and Performance, 1976, 6, 190-215.

Simpson, A. J., \& FitTER, M. J. What is the best index of detectability? Psychological Review, 1973, 80, 481-488.

Starr, S. J., Metz, C. E., Lusted, L. B., \& Goodenough, D. J. Visual detection and localization of radiographic images. Radiology, 1975, 116, 533-538.

Swets, J. A., Pickett, R. M., Whitehead, S. F., Getty, D. J., Schnur, J. A., Swets, J. B., \& Freeman, B. A. Assessment of diagnostic technologies. Science, 1979, 205, 753-759.

Van Der Heidden, A. H. C., \& Eerland, E. The effects of cueing in a visual signal detection task. Quarterly Journal of Experimental Psychology, 1973, 25, 496-503.

VAn Voorhis, S., \& Hillyard, S. A. Visual evoked potentials and selective attention to points in space. Perception \& Psychophysics, 1977, 22, 54-62.

(Received for publication October 12, 1979; revision accepted April 28, 1980.) 